\title{
Controle social, participação e desenvolvimento: as experiências dos Conselhos Regionais de Desenvolvimento (Coredes) no Rio Grande do Sul
}

\author{
Taciana Angélica Moraes Ribas ${ }^{1}$ \\ Sérgio Luis Allebrandt ${ }^{2}$ \\ Patrícia Härter Sampaio Stasiak ${ }^{3}$ \\ Luiza Fracaro Polleto ${ }^{4}$
}

\begin{abstract}
Resumo
Este trabalho se constituiu a partir de uma revisão de literatura narrativa acerca dos conceitos de Controle Social, Participação e Desenvolvimento, temáticas estas que têm sido amplamente debatidas no meio acadêmico, a fim de enfatizar a importância da participação da sociedade nas discussões sobre as ações dos governos que visem o desenvolvimento regional. Além da busca pelo entendimento dos conceitos, este artigo se baseou em estudos anteriores (dissertações de mestrado) que resultaram a partir de pesquisas realizadas no âmbito do Grupo Interdisciplinar de Estudos em Gestão e Políticas Públicas, Desenvolvimento, Comunicação e Cidadania (GPDeC), inserido no Programa de Pós-Graduação em Desenvolvimento Regional (PPGDR) - UNIJUÍ, que traz como exemplo os Conselhos Regionais de Desenvolvimento (Coredes). Este estudo é de abordagem qualitativa, de natureza explicativa, com enfoque no paradigma da teoria crítica. Como resultados, se observou que o aprofundamento do referencial teórico proporcionou um melhor entendimento aos pesquisadores acerca das temáticas, o que permitiu correlacionar estas teorias, com a análise das dinâmicas dos Coredes.
\end{abstract}

Palavras-chave: Controle Social. Participação. Desenvolvimento. Conselhos Regionais

\section{Social control, participation and regional development: the experiences of the regional development councils (Coredes) in Rio Grande do Sul}

\begin{abstract}
This research was produced from a revision of a narrative literature around the concepts of Social Control, Participation and Development, themes which have been being widely debated in the academic field, in order to emphasize the importance of the society's participation in the discussions about the governments'actions that aim the regional development. Beyond the search for the understanding of the concepts, this article was based in previous studies (mastering dissertations) which were results from researchs realized in the scope of the Interdisciplinary Group of Studies in Management and Public Policies, Development, Communication and Citizenship (GPDeC), inserted in the Post-Graduation Program in Regional Development (PPGDR) - UNIJUI, and that brings as example the Regional Development Councils (Coredes). This study is supported in a qualitative approach, of explanatory nature, spotlighted in the critical theory paradigm. As results, it was observed that the deepening of the theorical referential provided a better understanding for the researchers about the thematic, which allowed to correlate these theories, with the analysis of the Coredes' dynamics.
\end{abstract}

Keywords: Social Control. Participation. Development. Regional Councils

\footnotetext{
${ }^{1}$ Doutoranda em Desenvolvimento Regional (PPGDR/UNIJUÍ). Bolsista Prosuc/Capes. https://orcid.org/0000-0002-7255-3793 Email: taciana.ribas@sou.unijui.edu.br

2 Doutorado em Desenvolvimento Regional (PPGDR/UNISC). Professor do Programa de Pós-Graduação em Desenvolvimento Regional da UNIJUÍ. https://orcid.org/0000-0002-2590-6226 Email: allebr@unijui.edu.br

${ }^{3}$ Doutoranda em Desenvolvimento Regional (PPGDR/UNIJUÍ). https://orcid.org/0000-0002-9676-1028 Email: patricia-hs@hotmail.com
}

${ }^{4}$ Mestranda em Desenvolvimento Regional (PPGDR/UNIJUÍ). https://orcid.org/0000-0003-3973-5277 Email: polleto.luiza@gmail.com 


\section{Introdução}

Este trabalho teve por objetivo abordar sobre a importância da participação da sociedade no campo das políticas públicas que visem o Desenvolvimento Regional. Para isto, se pautou nos conceitos de Controle Social, Participação e Desenvolvimento, trazendo a experiências dos Conselhos Regionais de Desenvolvimento (Coredes).

Esta discussão se faz pertinente pois, para que o sujeito se torne um cidadão participativo, é imprescindível que se fortaleça os espaços públicos que propiciam esse debate, em que o indivíduo possa dialogar diretamente com os gestores públicos, podendo indicar quais as demandas/prioridades seriam de maior interesse da população, e estes interesses devem atender impreterivelmente o bem-estar e a coletividade.

Neste cenário, salienta-se que é preciso fortalecer espaços como estes (os conselhos), pois são eles que legitimam a participação da sociedade, sendo esta - participação, para além do processo eleitoral, em que passam de meros votantes, à sujeitos que se preocupam com o que ocorre no meio em que vivem.

Com isto, o Controle Social tem funções como prevenir a corrupção em complemento aos controles institucionais; apoia na ampliação da qualidade da ação estatal, trabalha a cultura de participação pública; pressupõe e estimula a participação popular e aproximação da Sociedade com Estado; corrige rumos da administração pública, e propicia a efetivação da democracia/participação cidadã (TENÓRIO, 2012).

Deste modo, este artigo vai moldando esses entendimentos de Controle Social, Participação e Desenvolvimento, a fim de traduzir o quanto essa temática favorece a emancipação do sujeito, tornando-o capaz de ser um ator importante no meio em que vive.

Assim, este trabalho, além desta introdução, apresenta os apontamentos metodológicos que traz os procedimentos de coleta de dados e da pesquisa; o referencial teórico, em que apresenta os conceitos de Controle Social, Participação e Desenvolvimento; os resultados e discussões que contextualiza a trajetória dos Coredes no Estado do Rio Grande do Sul, aonde também são apresentados os resultados de pesquisas anteriores realizadas no PPGDR/Unijuí, seguido das considerações finais com o parecer dos autores delineando os resultados com o referencial teórico, encerrando-se com as referências bibliográficas que balizaram este estudo. 


\section{Metodologia}

Este estudo inscreve-se no paradigma/enfoque da teoria crítica, a qual destaca o papel da ciência na transformação da sociedade, pois busca investigar a realidade dos grupos e instituições, relacionando as ações humanas com a cultura e as estruturas sociais e políticas, no objetivo de entender as redes de poder - como são produzidas, mediadas e transformadas (ALVES-MAZZOTTI, 2004; ALLEBRANDT, 2010). Essa abordagem é essencialmente relacional, já que procura investigar o que ocorre nos grupos e instituições relacionando as ações humanas com a cultura e as estruturas sociais e políticas, visando compreender como as redes de poder são produzidas, mediadas e transformadas (ALVES-MAZZOTTI, 1998 apud ALEBRANDT, 2010).

Trabalha-se como sendo uma revisão de literatura narrativa, pois esta não exige um protocolo rígido para sua confecção, uma vez que este método, apresenta uma temática mais aberta, em que as buscas das fontes não são pré-definidas e proporciona aos investigadores selecionar os artigos arbitrariamente, fornecendo informações sujeitas a viés de seleção, com grande interferência da percepção subjetiva (UNESP, 2015). Para isto, não se valeu de estratégias de busca para a seleção dos textos, e sim, foram utilizados autores que estão alinhados com o grupo de pesquisa, cuja temáticas foram publicadas em livros, artigos de periódicos, eventos científicos, seminários, etc.

Quanto aos objetivos é de natureza explicativa, pois como sugere Gil (2002), esse procedimento oportuniza uma maior aproximação com o problema, de modo a levantar suposições partindo de levantamento bibliográfico e/ou entrevistas com pessoas que tiveram contato com as práticas do problema estudado.

Acerca da abordagem, esta pesquisa é qualitativa pois não há uma preocupação com uma representatividade numérica, e está fundamentado na compreensão de um determinado grupo social ou organização (MINAYO, 2001). Há uma busca em clarificar o porquê das coisas, apresentando o que melhor convêm a ser feito, sem quantificar valores, uma vez que as trocas simbólicas não são submetidas à prova dos fatos, pois os dados analisados são não-métricos (suscitados e de interação) e se valem de diferentes abordagens.

Outro instrumento de coleta utilizado foi a matriz de categorias e critérios de análise, em que se trabalhou para analisar os resultados obtidos no Corede estudado. Neste artigo, optou-se em trabalhar apenas o critério de promoção do controle social associado a categoria do Controle Social, que considera se o conselho tem a capacidade em promover o controle social. 
Ainda, utilizou-se da observação não participante, em que os investigadores participaram de reuniões e debates e a análise documental por meio dos decretos, Leis e Estatutos.

\section{Referencial teórico: controle social, participação e desenvolvimento}

O conceito Controle Social tem sido evocado nos últimos anos, o qual tornou-se centro das discussões em meios acadêmicos e nas práticas recentes de diversos segmentos da sociedade como sinônimo de participação social nas políticas públicas.

O viés acerca de controle social abordado neste trabalho não é aquele tradicional adotado pela sociologia, em que controle social se referia às formas e mecanismos de controle do Estado sobre a sociedade. Priorizou-se aqui o conceito invertido, advindo da ciência política, que entende o controle social enquanto mecanismos, dinâmicas e espaços de controle da sociedade sobre o Estado, sobre as políticas públicas (RIBAS, 2017).

Correa (2000, apud FRANCISCO NETO, VILLELA, 2017), enfatiza que:

o termo controle social ganhou novos horizontes e compreensões em que houve uma evolução em torno do conceito de controle social que estava atrelado a noção de um controle do Estado sobre a população. O controle social firma-se em um novo espectro, como um instrumento de representação social sobre as ações da esfera estatal.

Pode-se dizer que o conceito de controle social, derivou da gestão social, o qual se apropriou de elementos que os conectam, como a ideia ter a participação da sociedade civil (como protagonista) na elaboração, acompanhamento e verificação (ou monitoramento) das ações da gestão pública. O que, para Tenório (2012), indica que a sociedade passa atuar, sugerindo e definindo diretrizes, realizando diagnósticos, indicando prioridades, deliberando acerca de programas e ações, avaliando os objetivos, os processos e os resultados obtidos.

Esta é uma nova ótica acerca da implementação das políticas públicas, a qual coloca o sujeito como protagonista no planejamento das ações do gestor público, em que o governo ao delinear um determinado programa ou política pública, não toma as decisões a partir de seu olhar. Neste modelo, o gestor passa a interagir com os diferentes atores da sociedade que hoje fazem parte do processo democrático de participação, na qual eles ajudam a elencar e sugerir as demandas recrutadas, tendo por base os anseios e necessidades locais nas diversas dimensões socioeconômicas e culturais (ALLEBRANDT, RIBAS, POLETTO, FRIEDRICH, 2018). 
Na linha de pensando do Controle Social, entende-se ainda que para que ele ocorra, deve existir mecanismos formais - consultivos e deliberativos, que estão presente nos espaços públicos, onde a atuação seria para além do momento eleitoral, que seria:

\begin{abstract}
fiscalizar ações governamentais nas mais diversas áreas e de formas distintas; interceder abertamente quanto à formulação e implementação de políticas públicas; e canalizar opiniões e interesses dos grupos politicamente organizados em determinado tema com o objetivo de ouvi-los quanto à execução de políticas. Em outras palavras, controle social diz respeito à possibilidade do Estado (que não é neutro, embora objetive igualdade jurídico-política e socioeconômica) ser controlado pelos mais diversos grupos sociais que conflitam na sociedade (TENÓRIO, 2016, p. 27-28).
\end{abstract}

O Ministério do Desenvolvimento Social - MDS conceitua Controle Social como uma teoria que tem como base a participação do cidadão na gestão pública, estando o sujeito à frente da fiscalização, monitoramento e no controle das ações do gestor público no acompanhamento das políticas públicas. "Controle Social é um importante mecanismo de fortalecimento da cidadania que possibilita compartilhar responsabilidades e proporciona transparência às ações do poder público" (MDS, 2015 apud FRANCISCO NETO, VILLELA, 2017).

Ainda, para Tenório (2016a, p.23) o Controle Social se "caracteriza-se por ter origem nos direitos fundamentais e diversos são os significados para esse tipo de direito: liberdades públicas, direitos do homem, direitos humanos e direitos subjetivos". Para ele, é na origem dos direitos que se explica a existência da participação popular e do controle social das atividades do Estado, pois a Carta Magna estabelece estes direitos como fundamentais para a vida do cidadão, e o Estado é o responsável para a garantia destes direitos (TENÓRIO, 2016a).

Por Controle Social, Paz (2002), indica que este ambiente propicia o envolvimento da sociedade na fiscalização, acompanhamento e avaliação da gestão pública no que se refere a execução das ações e a aplicação dos recursos financeiros destinados à implementação de uma política pública. Em suma, significa dizer que, é por meio dos instrumentos de controle social que se percebe a capacidade de intervenção nas políticas públicas, tendo os sujeitos como protagonistas, interagindo com o Estado na definição de prioridades e na elaboração dos planos de ação para o município, estado, ou o governo federal.

Neste sentido, é possível dizer que o controle social está alicerçado no ambiente dos instrumentos que orientam a participação da sociedade no contexto de aplicação de recursos, a 
fim de proporcionar mais qualidade de vida a todos, oportunizando a sociedade a exercer sua cidadania, a partir da percepção de seus direitos e deveres (RIBAS, 2017, p. 47).

Com isto, podemos perceber o quanto os processos que incluem a participação da sociedade nos espaços de poder e decisão, por meio das ações participativas, colocam o sujeito como um articulador entre a sociedade e o governo, ampliando assim, seu potencial como ator no que diz respeito a sugerir, propor, articular, implementar políticas públicas, tornando-o protagonista da sua própria história. Assim, quanto mais o cidadão puder vislumbrar que quanto melhor compreender o meio em que vive, essa visão o tornará um agente transformador de mudança na sociedade.

Participar é um processo que está em constante transformação e que, em sua essência, é uma conquista processual, contínua e muitas vezes prolongada. "Não existe participação suficiente, nem acabada" (Demo, 1993 apud Tenório 2016),

\begin{abstract}
a participação é um processo de conquista, não somente na ótica da comunidade ou dos interessados, mas também do técnico, do professor, do pesquisador, do intelectual. Todas estas figuras pertencem ao lado privilegiado da sociedade, ainda que nem sempre ao mais privilegiado. Tendencialmente buscam manter e aumentar seus privilégios. Se o processo de participação for coerente e consistente, atingirá tais privilégios, pelo menos no sentido de que a distância entre tais figuras e os pobres deverá diminuir (DEMO, 1993, apud TENÓRIO, 2016, p. 18).
\end{abstract}

Sendo assim, partindo da constatação de que a participação integra o cotidiano de todos os indivíduos, Tenório e Rozenberg (1997, apud ALLEBRANDT, 2010 p. 51), afirmam que

\begin{abstract}
ao longo da vida e em diversas ocasiões somos levados, por desejo próprio ou não, a participar de grupos e atividades. $\mathrm{O}$ ato de participar, tornar-se parte, revela a necessidade que os indivíduos têm em se associar na busca de alcançar objetivos que Ihes seriam de difícil consecução ou até mesmo inatingíveis caso fossem perseguidos individualmente, de maneira isolada.
\end{abstract}

Neste caminho, "a participação requer consciência sobre seus atos, devendo a mesma, ser conquistada e voluntária, para que seja entendida como cidadania participativa" (Tenório e Rozenberg 1997, apud ALLEBRANDT, 2010). A participação não deve ser imposta nem doada, mas conquistada (DEMO 1991, apud ALLEBRANDT, 2010). 
Para Allebrandt (2010, p. 52),

as pessoas envolvidas em um processo de participação devem ter a compreensão daquilo que estão vivenciando, logo não podem simplesmente agir sem entender as razões e consequências da sua ação, pois, neste caso, a participação não passa de adestramento, presente nos processos de dominação que, entre outros aspectos, negam o acesso à informação e à educação às pessoas.

Percebe-se que o indivíduo/sujeito é muito importante no contexto da participação e nos processos de decisão, pois isto o torna cidadão usufruidor de seus direitos e deveres na sociedade no que diz respeito aos interesses da coletividade. Sendo assim, é possível perceber que a participação consciente e apropriada ajudará a aprimorar os índices de eficácia e efetividade das políticas públicas, sobretudo quando as pessoas passam a ter um olhar para o bem comum.

Deste modo avalia-se que o grande desafio é transformar o cidadão passivo em ativo, ou cidadão deliberativo (TENÓRIO, 2007), de modo que possa exercer seus direitos políticos, não sendo apenas participante nas eleições com seu voto nas urnas, mas sim, incentivado- o a participar mais ativamente na comunidade de forma que as decisões venham pela soberania popular.

Quando falamos em Controle Social, pressupõe-se participação. Remete-se a uma sociedade que participa dos espaços públicos com a finalidade de participar/atuar nas tomadas de decisão relacionadas ao coletivo, às políticas públicas, que possibilitem o desenvolvimento regional gerando uma melhor qualidade de vida a todos.

Acerca das discussões sobre desenvolvimento, tem se a ideia de que a sociedade é parte fundamental no desenvolvimento, em que sua participação se torna extremamente relevante nas discussões de políticas públicas, se integrando a todas as dimensões que compõem o desenvolvimento. Pois não tem como dissociar o sujeito das questões do desenvolvimento, pois sem ter o cidadão, não haveria por que e para quem desenvolver.

Segundo Brandão (2007), a participação da sociedade nas discussões acerca do desenvolvimento marca o estado democrático da cidadania, e, discutir o desenvolvimento tendo por base o localismo, centra no sentido de que é na comunidade/sociedade, como sendo o local onde tudo parte e o local onde tudo chega.

No entanto, o mesmo autor enfatiza que o localismo por si só, não tem argumentos suficientes para se ter ações exitosas de desenvolvimento, e lançou o desafio de uma ótica que 
ele chamou de multiescalar em que se trabalharia todas as questões de multiplicidade de cada território, ou seja, "as heterogeneidades estruturais, diversidades e desigualdades como um campo interessante de diversidade de um país continental muito rico e complexo em todos os sentidos, estaria em primeiro plano", isso tudo, sem deixar de lado a participação da sociedade.

O desenvolvimento decorre de dinâmicas territoriais, que ocorrem por meio de um conjunto de fatores e ações que englobam os agentes/sociedade e seus interesses diretos ou indiretos (social, econômicos, ambiental, cultural e político), dentro de um espaço, de uma dimensão global, que dentro das ciências sociais pode ser compreendida como local, regional ou dentro de um território (DALLABRIDA, 2007).

Acerca de recorte do território, para se estudar o desenvolvimento Dallabrida et al (2015, p. 23), aponta que este pode ser dividido "a partir de regiões administrativas, metropolitanas, áreas de abrangência de comitê de bacias hidrográficas, um município ou parte dele, um bairro ou até mesmo a área de abrangência de experiências de Indicação Geográfica - IG".

Neste caso, este recorte proporciona uma condição necessária para que ocorra uma maior participação popular, efetivando a cidadania, onde os sujeitos poderão opinar no destino de seu entorno espacial (DALLABRIDA et al, 2015).

Com isto, a concepção de território, está pautada na

fração do espaço historicamente construída através das inter-relações dos atores sociais, econômicos e institucionais que atuam no âmbito espacial, apropriada a partir de relações de poder sustentadas em motivações políticas, sociais, ambientais, econômicas culturais ou religiosas, emanadas do Estado, de grupos sociais ou corporativos, instituições ou indivíduos (DALLABRIDA, 2011).

Deste modo, o desenvolvimento do território sugere a participação de protagonistas atuando em uma ação integrada, planejando e executando tais ações, promovendo o desenvolvimento deste território (DALLABRIDA et al, 2015).

Boisier (2001, p. 6), faz uma distinção entre: desenvolvimento territorial, regional e local. Para ele a ideia de desenvolvimento territorial, está mais pautado à escala geográfica de um processo e não à sua substância. "É uma escala contínua na qual é possível reconhecer os seguintes "cortes": mundo, continente, país, região, estado ou província ou departamento, comuna e, em certos casos, "calçadas", "municípios" ou outras categorias menores". Acerca do desenvolvimento regional, para ele, está embasado a "um processo de mudança estrutural 
localizada em uma área territorial chamada região, que está imbricada a um processo permanente de progresso na própria região, na comunidade ou sociedade que a habita e em cada membro individual da região". Em relação ao Desenvolvimento Local este "[...] é processo endógeno registrado em pequenas unidades territoriais e grupos humanos capazes de promover o dinamismo econômico na qualidade de vida da população" (BOISER, 2001, p. 9).

Constata-se que desenvolvimento, seja local, regional ou territorial, está atrelado à sociedade e aos seus anseios, de modo a assegurar a legitimidade das ações que realmente sejam pertinentes para o desenvolvimento homogêneo e eficaz, olhando sempre para as peculiaridades de cada local, sincronizando, sociedade e Estado (RIBAS, 2017, p. 49).

De modo geral, pode-se pensar em um conceito basilar de desenvolvimento aplicável a local, regional e territorial, pois na medida em que se pensa em políticas locais, também está se pensando em políticas regionais e territoriais.

O desenvolvimento (local, regional, territorial) pode ser entendido como um processo de mudança estrutural empreendido por uma sociedade organizada territorialmente, sustentado na potencialização dos recursos e ativos (genéricos e específicos, materiais e imateriais) existentes no local, com vistas à dinamização socioeconômica e a melhoria da qualidade de vida de sua população (DALLABRIDA, 2011, p. 19).

Allebrandt (2018) e Tenório, Dutra e Magalhães (2004) entendem que as discussões sobre o desenvolvimento iniciam através do local, a partir dos próprios atores locais, onde, por meio deles, focalizam nas ações de desenvolvimento com demandas/prioridades e apelo local, ao invés da ótica do planejamento centralizado. "O desenvolvimento local é determinado ou condicionado por um conjunto de dimensões: econômica, social, cultural, ambiental e físicoterritorial, político-institucional e científico-tecnológica, dimensões que mantêm relativa autonomia umas em relação às outras (ALLEBRANT, 2018, p.22)".

Enfim, são vários os entendimentos acerca do que é desenvolvimento ou de como ele ocorre, mas percebe-se que todos acabam por ter o sujeito como personagem principal neste cenário, atuando por meio dos mecanismos de controle social. Deste modo, o desenvolvimento está atrelado à sociedade e aos seus anseios, de modo a assegurar a legitimidade das ações que realmente sejam pertinentes para o desenvolvimento homogêneo e eficaz, olhando sempre para as peculiaridades de cada local sincronizando sociedade e Estado. 


\section{Resultados e discussões}

Este item está subdividido em duas partes. A primeira relata brevemente a história da criação dos Coredes e suas dinâmicas de funcionamento, enfatizando a importância deste espaço público como espaço que propicia a participação da sociedade nas discussões que visem o desenvolvimento. A segunda parte, traz o exemplo do Corede Missões como promotor do controle social. Ao final, é perceptível que, o modelo de funcionamento destes conselhos, estão alinhados com os conceitos de Controle Social e Participação e objetivam o Desenvolvimento local e Regional.

\subsection{Os conselhos regionais de desenvolvimento como articuladores do controle social}

Este trabalho objetiva abordar sobre os mecanismos de Controle Social que possibilitam a participação efetiva da sociedade nas ações do Gestor Público que visem o Desenvolvimento Regional.

Assim, é importante abordarmos sobre os Coredes, conselhos que foram instituídos no Estado do Rio grande do Sul, e são entendidos como arranjos institucionais que se constituem enquanto espaços públicos orientando a intermediação da sociedade civil com o Estado, nas esferas municipal, estadual e federal. São espaços que propiciam a discussão, decisão e interação de políticas, ações, lideranças e definição de recursos que objetivam o desenvolvimento regional do RS.

No entanto, antes da criação dos Coredes, nos anos de 1987 a 1990, durante o governo de Pedro Simon, se percebeu a necessidade da implementação de ações que facilitassem a integração entre o Estado, os municípios e as comunidades locais. Neste sentido foi elaborado o Programa Estadual de Descentralização Regional (PEDR), que foi instituído pelo Decreto № 32.567 de 02 de Outubro de 1987 que visava "[...] implementar a descentralização das atividades setoriais da Administração Estadual direta e indireta, com base em regiões territoriais[...]" (RIO GRANDE DO SUL, 1987).

O PEDR aponta, entre os seus objetivos, três que definem acerca da participação da sociedade, como já foi mencionado por SIEDENBERG, BÜTTENBENDER, ALLEBRANDT (2011, p. 204) 
[...] buscar a articulação da comunidade regional e sua participação nas definições e decisões sobre prioridades para sua região, bem como na gestão e no controle de recursos alocados para a mesma; obter a racionalização das ações setoriais do Governo Estadual, como novas formas de administração descentralizada, e a participação da comunidade como suporte aos programas de desenvolvimento; assegurar a participação do planejamento regional no processo de planejamento global do Estado, através da definição dos objetivos, das potencialidades, das necessidades e das prioridades regionais, [...] transmitindo-os ao Estado para fins de agregação dos mesmos ao plano estadual.

Desde modo, Allebrandt (2010, p. 93), comenta que "é por meio deste Decreto, que se verifica a preocupação do governo com a reorganização da máquina pública estadual, principalmente em relação à necessidade em avançar no caráter participativo".

Durante o Governo Collares (1991 a 1994), se manteve acessa a ideia de ter a sociedade participando das ações da administração, e foi neste período que experiências de participação popular foram implantadas por meio da criação de Conselhos Populares, que mais tarde, acabaram norteando a criação dos Conselhos Regionais de Desenvolvimento (Coredes).

Com isto, esse caráter participativo de democracia, começa a ganhar forma, e coloca o cidadão, não apenas como coadjuvante em momentos como os de eleições, em que apenas é almejado o seu voto, e sim, como peças importantes tornando os sujeitos em atores, protagonistas do controle social por meios dos mecanismos/arranjos institucionais como exemplo: os Coredes.

A experiência e a trajetória dos Coredes são consideradas uma estratégia pioneira de organização regional no Brasil, "[...] onde a estrutura institucional, os mecanismos de participação social, as formas de encaminhamentos das demandas regionais, o amadurecimento dos processos e relações entre governo e sociedade foram sendo aperfeiçoados ao longo do tempo [...]" (BÜTTENBENDER, SIEDENBERG, ALLEBRANDT, 2011, p. 311).

A criação dos Coredes teve início em 1991, por iniciativa articulada entre a sociedade civil organizada nas regiões e o Governo do Estado. Em 1994 foram reconhecidos e institucionalizados pela Lei $n$ o 10.283 de 17 de outubro e seu funcionamento e organização foi regulamentada pelo Decreto no 35.764 de 28 de dezembro de 1994. O quadro 1 apresenta a cronologia de criação dos 28 Coredes, que ocorreu gradativamente entre 1991 e 2008.

Ao todo, foram instituídos 28 Coredes no Rio Grande do Sul, distribuídos em 9 Regiões Funcionais -RF (Figura 1 e Quadro 2). “Esta regionalização considerou critérios de 
homogeneidade econômica, ambiental e social e na adequação das variáveis correspondentes de identificação das polarizações (empregos, transportes, rede urbana, saúde e educação superior)" (BÜTTENBENDER, SIEDENBERG, ALLEBRANDT. 2011a, p. 100).

Quadro 1 - Datas de criação dos Coredes no RS

\begin{tabular}{|c|c|c|c|c|}
\hline Ano & Data & Ordem & Região & № Atual de Municípios \\
\hline \multirow{17}{*}{1991} & \multirow{3}{*}{14 de Junho } & 1 & Central & 19 \\
\hline & & 2 & Noroeste Colonial & 11 \\
\hline & & 3 & Produção & 23 \\
\hline & 26 de Julho & 4 & Hortências & 07 \\
\hline & 03 de Agosto & 5 & Fronteira Noroeste & 20 \\
\hline & 16 de Agosto & 6 & Norte & 32 \\
\hline & 18 de Agosto & 7 & Litoral Norte & 21 \\
\hline & \multirow{2}{*}{30 de Agosto } & 8 & Missões & 25 \\
\hline & & 9 & Nordeste & 19 \\
\hline & 20 de Setembro & 10 & Fronteira Oeste & 13 \\
\hline & 25 de Outubro & 11 & Alto do Jacuí & 14 \\
\hline & 09 de Novembro & 12 & Médio Alto Uruguai & 23 \\
\hline & 22 de Novembro & 13 & Sul & 22 \\
\hline & 05 de Dezembro & 14 & Serra & 31 \\
\hline & 19 de Dezembro & 15 & Vale do Rio Pardo & 23 \\
\hline & \multirow{2}{*}{20 de Dezembro } & 16 & Vale do Taquari & 36 \\
\hline & & 17 & Centro Sul & 17 \\
\hline \multirow{2}{*}{1992} & 09 de Janeiro & 18 & Vale do Caí & 19 \\
\hline & 25 de Fevereiro & 19 & Campanha & 07 \\
\hline 1993 & 02 de Julho & 20 & Paranhana - Encosta da Serra & 10 \\
\hline 1994 & 05 de Julho & 21 & Vale do Rio dos Sinos & 14 \\
\hline 1996 & 09 de Dezembro & 22 & Metropolitano do Delta do Jacuí & 10 \\
\hline 2002 & 14 de Junho & 23 & Alto da Serra do Botucaraí & 16 \\
\hline 2004 & 07 de Julho & 24 & Jacuí - Centro & 07 \\
\hline \multirow{2}{*}{2006} & \multirow{2}{*}{28 de Dezembro } & 25 & Campos de Cima da Serra & 10 \\
\hline & & 26 & Vale do Rio da Várzea & 17 \\
\hline \multirow{2}{*}{2008} & \multirow{2}{*}{10 de Janeiro } & 27 & Celeiro & 21 \\
\hline & & 28 & Vale do Rio Jaguari & 09 \\
\hline
\end{tabular}

Fonte: Siedenberg, Büttenbender, Allebrandt (2011, p. 314) 
Os Conselhos Regionais de Desenvolvimento "têm constituição jurídica própria em cada região, sendo que o foro jurídico se aplica na cidade de referência onde está instalada sua sede político-administrativa" (BÜTTENBENDER, SIEDENBERG, ALLEBRANDT, 2011, p. 315), e funcionam por meio da participação, discussão e deliberação, que ocorrem nas assembleias ou reuniões ordinárias ou extraordinárias, seguindo o estatuto social ou regimento interno próprio.

Figura 1 - Mapa dos Coredes e Regiões Funcionais de planejamento

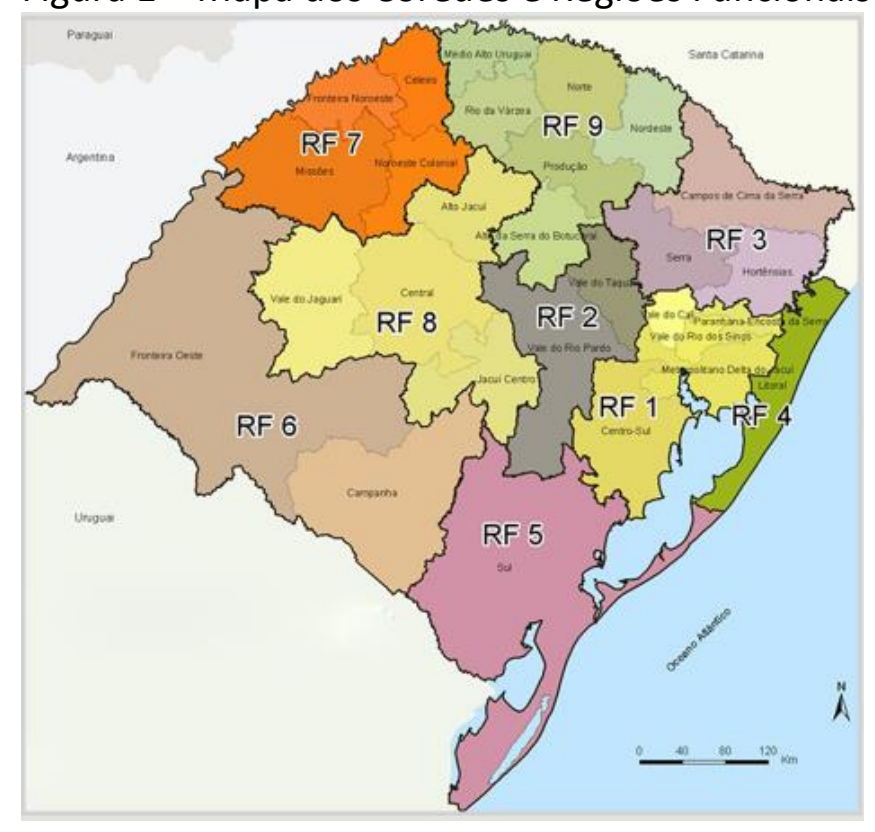

Fonte: Atlas Socioeconômico/RS

Os Coredes, de acordo com o Art. 2으, têm por objetivo promover o desenvolvimento regional de forma harmônica e sustentável, através da integração dos recursos e das ações de governo na região; proporcionar à melhoria da qualidade de vida da população, tratar de forma equitativa acerca da distribuição da riqueza produzida; estimular a permanência do homem em sua região e preservação e recuperação do meio ambiente.

No que diz respeito à competência, destaca-se aqui as mais relevantes, que são: promover a participação de todos os segmentos da sociedade; elaborar planos estratégicos de desenvolvimento regional; manter espaço permanente de participação democrática; orientar e acompanhar, de forma sistemática, o desempenho das ações dos Governos Estadual e Federal na região e respaldar as ações do Governo do Estado na busca de maior participação nas decisões nacionais (LEI № 10.283). 
Quadro 2 - Coredes e respectivas Regiões Funcionais (RF)

\begin{tabular}{|l|l|}
\hline Região Funcional (RF) & Coredes \\
\hline RF1 & $\begin{array}{l}\text { Metropolitano do Delta do Jacuí, Centro Sul, Vale do Caí, Vale do Rio dos Sinos e Pa- } \\
\text { ranhana- encosta da serra }\end{array}$ \\
\hline RF2 & Vale do Rio Pardo e Vale do Taquari \\
\hline RF3 & Campos de Cima da Serra, Hortênsias e Serra \\
\hline RF4 & Litoral Norte \\
\hline RF5 & Sul \\
\hline RF6 & Campanha e Fronteira Oeste \\
\hline RF7 & Fronteira Noroeste, Missões, Noroeste Colonial e Celeiro \\
\hline RF8 & Alto Jacuí, Central, Jacuí-Centro e Vale do Jaguari \\
\hline RF9 & $\begin{array}{l}\text { Alto da Serra do Botucarai, Médio Alto Uruguai, Nordeste, Norte, Produção e Rio da } \\
\text { Várzea }\end{array}$ \\
\hline
\end{tabular}

Fonte: RIBAS 2017, p. 57.

Em relação às atividades desenvolvidas pelos Coredes, pode-se dizer que por ser um espaço que propicia a interlocução entre a sociedade civil e o estado, o mesmo tem um papel de extrema importância, o qual, deve seguir um comportamento de imparcialidade no desempenho de suas atividades. São elas: discutir e produzir diagnósticos regionais, visando à elaboração dos Planos Estratégicos de Desenvolvimento Regionais e Estadual; fiscalizar a qualidade dos serviços prestados pelos órgãos estaduais; e, colaborar na busca de fontes alternativas de recursos para o financiamento de investimentos públicos.

Em relação aos integrantes dos Coredes, o estatuto prevê a participação de membros natos e representantes. São considerados membros natos os deputados estaduais e federais com domicílio eleitoral na região de abrangência do Conselho; prefeitos municipais e presidentes de Câmaras de Vereadores; presidentes dos Conselhos Municipais de Desenvolvimento - Comudes.

Como representantes (não natos), podem participar membros dos partidos políticos; dos órgãos dos Governos Estadual e Federal de caráter regional; das instituições de ensino superior que atuam na região; associações, sindicatos, conselhos setoriais, criados por lei, enquanto membros da sociedade civil organizada, provenientes dos seguintes segmentos sociais: empresários e trabalhadores da indústria, do comércio e do setor de serviços; empresários e trabalhadores rurais; cooperativas e associações de produtores; movimentos sociais organizados em caráter permanente na região; outras entidades da sociedade organizada.

A estrutura organizacional é composta pelos seguintes órgãos: Assembleia Geral Regional; Conselho de Representantes; Diretoria Executiva e Comissões Setoriais. A Assembleia Geral Regional é o órgão máximo de deliberação do conselho e deve ser composta por 
representantes da sociedade civil e dos poderes públicos existentes na região, observando sempre a paridade entre trabalhadores e empregadores. Cada um destes órgãos tem competências e atuações que estão previstas no Estatuto.

Os Coredes têm a missão de "ser espaço plural e aberto de construção de parcerias sociais e econômicas, em nível regional, por meio da articulação política dos interesses locais e setoriais em torno de estratégias próprias e específicas de desenvolvimento para as regiões do Rio Grande do Sul" (COREDES, 2010).

Sobre a Visão, os Conselhos devem

[...] articular os atores sociais, políticos e econômicos das regiões, inclusive colaborando para organizar os segmentos desorganizados, transformando-os em sujeitos coletivos capazes de formular suas próprias estratégias de desenvolvimento e, assim, serem construtores de seu próprio modelo de desenvolvimento regional (COREDES, 2010, p. 14).

Os objetivos estratégicos atuais dos Coredes são: formular e executar estratégias regionais, consolidando-as em planos estratégicos de desenvolvimento regional; avançar a participação social e cidadã, combinando múltiplas formas de democracia direta com representação política; constituir-se em instância de regionalização das estratégias e das ações dos Poderes Executivo, Legislativo e Judiciário do Rio Grande do Sul, conforme estabelece a Constituição do Estado; avançar na construção de espaços públicos de controle social dos mercados e dos mais diversos aparelhos do Estado; conquistar e estimular a crescente participação social e cidadã na definição dos rumos do processo de desenvolvimento gaúcho; intensificar o processo de construção de uma organização social pró-desenvolvimento regional (COREDES, 2010).

A atuação dos Coredes está fundamentada nos princípios da promoção do desenvolvimento regional; autonomia; pluralidade e identificação de consensos; confiança, cooperação e formação e parcerias; integração, articulação e consolidação das identidades regionais; busca da regionalização das políticas de desenvolvimento; aumento permanente da representatividade e o estado do Rio Grande do Sul visto a partir do desenvolvimento regional da organização e apoio à continuidade das políticas de interesse regional.

Percebe-se que os Coredes estão bem fundamentados e tem um papel importante no sentido de assegurar a participação da sociedade na gestão pública, servindo de interlocutor entre o Governo do Estado e dos municípios com a sociedade civil, permitindo que a mesma seja 
participante nas decisões que visem o desenvolvimento regional e uma melhor qualidade de vida a todos.

\subsection{Promoção do controle social no desenvolvimento regional no Corede Missões}

Para exemplificar o exposto acerca do controle social, participação, desenvolvimento e a criação dos Coredes, este trabalho traz uma pequena parte dos resultados obtidos em estudos realizados no Corede Missões, em que se avalia como ocorre a promoção do controle social no Desenvolvimento Regional, tendo por base o Corede.

O critério de promoção do controle social, tem por objetivo verificar se os Coredes têm à capacidade de promover o controle social. Verificou-se que o Corede Missões promove o controle social, na medida em que se fomenta o processo de discussão nas comunidades, nos bairros, nas mais diferentes entidades. Isso pode ser constatado, pois os entrevistados fizeram referência ao processo de elaboração do planejamento participativo regional, que ocorreu em todas as 28 regiões dos Coredes gaúchos durante 2016 e 2017, em que houve a participação dos representantes dos conselhos.

Neste caminho, a partir do momento em que a população esteve presente nas discussões que elaboraram o Plano de Desenvolvimento de forma participativa, que isto qualifica a região para entender melhor sua realidade socioeconômica, cultural e ambiental, e facilita o processo de consultas populares futuras, que passam a ter uma referência sistemática de prioridades e diretrizes regionais para o processo de desenvolvimento.

Assim se verifica que a promoção do controle social ocorre quando os sujeitos de direitos se associam com o objetivo de desenvolver ações organizadas. Esta deve ser praticada pelas entidades, associações, sindicatos, escolas, poder legislativo, executivo, conselhos gestores, além dos Comudes e do Corede.

São os atores sociais que intervêm, promovendo o controle social em seus espaços de atuação, contribuindo diretamente para o bem comum. Espaços públicos ampliados, abertos a qualquer cidadão, são vistos como condição para qualificar a participação social e o controle social das políticas públicas e do desenvolvimento.

Constatou-se que os entrevistados entendem que para que houvesse a promoção do controle social, seria ideal "ampliar a participação da sociedade, através das conferencias 
municipais", o que resultaria no controle social, para além dos conselheiros, incluindo o sujeito/cidadão nessas discussões, tornando- o em um importante agente de mudança.

Outra questão observada, é acerca de que para que ocorra a promoção do controle social é necessário melhorar a participação da sociedade, fomentando e garantindo a democracia e desenvolvendo ações que cultivem a cultura da participação dos diferentes segmentos dos municípios, "[...]é necessário fomentar um intenso processo de participação, com reuniões permanentes, com diversos setores, com diversos seguimentos, com os diferentes públicos, isso precisa ser exercitado (extraído da fala de um entrevistado)".

No que diz respeito à promoção do controle social, tendo por base o debate entre os conselheiros, os representantes da sociedade e os gestores públicos, se verificou que para que isso ocorra, é fundamental que os movimentos sociais, fóruns, associações, conselhos e outras entidades de caráter democrático, procurem sempre informações atuais acerca dos programas e das políticas públicas que estão em pauta ou em andamento, para posteriormente debater com os governos. Com isto terão mais subsídios para chegar nos espaços de participação e debater e deliberar com mais propriedade alguma demanda já discutida anteriormente.

Na análise dos resultados, percebeu-se que Corede Missões, está sempre sugerindo que ocorram discussões relevantes para o desenvolvimento. Isso aponta que este conselho tem sim, a preocupação em promover o controle social. No entanto, há o contraponto, em que se percebe ser necessário melhorar a participação da sociedade, fomentando e garantindo a democracia e desenvolvendo ações que cultivem a cultura da participação dos diferentes segmentos nos municípios da região.

Cabe ainda elencar, de que a maioria dos entrevistados demonstrou a preocupação de que deveria haver dinâmicas periódicas de capacitação, de formação dos representantes e participantes dos processos participativos. O processo educativo é essencial para uma cultura de política participativa, não apenas nos Coredes, como também, em outros processos de discussão e deliberação, como as Audiências Públicas, Assembleias, Consulta Popular, Orçamento Anual, PPA, etc.; uma vez que estes espaços públicos se constituem em verdadeira escola de democracia.

Por fim, neste quesito sobre o Corede, ser um protagonista da promoção do controle social, se verificou que este busca promover o controle social, bem como, percebem que os conselheiros são capazes de atuarem como agentes promotores do controle social, no entanto, 
falta muita autonomia aos conselhos, pois ainda estão muito atrelados ao executivo, atuando fortemente apenas no período da Consulta Popular.

\section{Considerações finais}

Ao trabalhar os conceitos de Controle Social, Participação e Desenvolvimento, foi possível perceber que de acordo com Büttenbender, Siedenberg e Allebrandt (2011, p. 330), estes afirmam que "a qualificação da ação cidadã ou assistencialistas devem ligar à formação de conselhos negociados com a transparência e profissionalismo, visando a melhoria das condições de vida da sociedade e o desenvolvimento regional".

Ainda acrescentam que "a participação e a cidadania devem ser entendidas como um processo de construção contínua, cujos espaços precisam ser conquistados e, sobretudo, ampliados pela população, desacostumada da atividade em função de um centralismo político vigente no Brasil por várias décadas".

Deste modo, é por meio de espaços públicos, como os Coredes que essa participação pode ser efetivada, pois estes são instâncias legais e regulamentadas que ao instituir-se cumpre o papel de planejar a política adequada (ação coletiva) para a promoção do desenvolvimento local e regional. Baseando-se em pesquisa preliminar, através do relato dos representantes dos Coredes, assim como, a partir de documentos disponibilizados por estes observa-se que a maioria das instâncias dos Coredes se atém a função interna deste instrumento político que deveria expressar a opinião da sociedade de forma democrática, coletiva e participativa.

No entanto, é preciso que este espaço tenha maior visibilidade e que seja fortalecido, para que possam de fato, promover o controle social, pois o que ocorre é uma prática política que funciona mais em algumas épocas do ano, como exemplo, para escolha de demandas da Consulta Popular. Assim, este conselho estaria cumprindo seu papel de servir como instrumentador do controle social, alicerçados na representação participativa, sendo um articulador das políticas públicas que promovam o desenvolvimento regional que realmente manifestem a vontade coletiva em virtude das necessidades da sociedade.

Ao avaliar a trajetória dos Coredes, de acordo com a visão de Büttenbender, Siedenberg, Allebrandt (2011a), esta pode ser considerada uma experiência pioneira e emergente, em permanente processo de aprimoramento e de transformação. As mudanças da sociedade e inovações nas políticas públicas de desenvolvimento oferecem, também aos Coredes e aos 
distintos e diferentes modelos de descentralização político-administrativa, o desafio da qualificação, da capacitação de suas lideranças, do planejamento, da gestão e da avaliação permanente.

No entanto, há muito espaço ainda para que o cidadão gaúcho se apodere de seus direitos e se conscientize que sua participação no processo não se restringe apenas à dimensão consultiva; também "é necessário desenvolver sua capacidade requisitiva, propositiva e de efetivo controle dos processos[...]" (Büttenbender, Siedenberg, Allebrandt (2011a).

Esta preocupação em envolver a sociedade nas discussões com o gestor público, também é incentivada na Constituição do Estado do Rio Grande do Sul de 1989, a qual incorpora diversos mecanismos de participação da população no processo de formação, formulação, implementação e avaliação das políticas públicas e define orientações ou normas para o processo de desenvolvimento e planejamento regional, além de manter aqueles já previstos obrigatoriamente na Constituição Federal (ALLEBRANDT, 2010, p. 237)

Desta forma, os Coredes são espaços públicos fundamentais para o exercício da cidadania, em que a sociedade pode legitimar sua participação apoiando o gestor público na elaboração e definições das políticas públicas, bem como na aplicação dos recursos, indicando qual a melhor ação a ser realizada que contemple as necessidades da população, resultando no desenvolvimento regional. Espaços públicos como estes, são de extrema importância para se discutir questões de desenvolvimento, oportunizando um espaço participativo, com debates que levam em conta os anseios da população.

Assim, este trabalho atingiu seus objetivos, que era trabalhar os conceitos de Controle Social, Participação e Desenvolvimento, no intuito de trazer a importância de ter o sujeito participando nas discussões que avaliam quais as ações são mais determinantes para o desenvolvimento de uma determinada localidade, região ou território, pois podem ser interlocutores da sociedade com os governantes. Ainda, se verifica que ações que coloquem a sociedade no cerne das discussões acerca da melhor aplicação dos recursos públicos, para que ocorra um desenvolvimento voltado ao bem da coletividade, estão em acordo com o referencial teórico que norteou este estudo.

Finalmente, é importante enfatizar, que desde março de 2020, estamos vivendo em um cenário de pandemia mundial, a covid-19; a sociedade, assim como todos os setores ficaram abalados, e espaços como os conselhos, também estão precisando se reinventar para manter acesa a chama da participação da sociedade nestes espaços públicos. Com isto, ficam alguns 
questionamentos: quais ações poderão/deverão ser desenvolvidas pelos Coredes em apoio ao desenvolvimento, uma vez que, se percebe um abalo geral na economia? Como estes conselhos estão atuando frente à pandemia? Deste modo, apontamos a continuidade deste estudo, em que será avaliado a atuação destes conselhos frente a pandemia, bem como, analisando como estão ocorrendo os processos participativos de controle social.

\section{Referências}

ALLEBRANDT, S. L. Escopo Teórico. In ALLEBRANDT, S. L., TENÓRIO F.G. (Orgs). Controle Social de Territórios: Teoria e práticas. Ijuí: Unijuí. 2018. p. 17 a 28.

Cidadania e gestão do processo de desenvolvimento: um estudo sobre a atuação dos conselhos regionais e municipais de desenvolvimento do Rio Grande do Sul, de 1990 a 2009. Santa Cruz do Sul. 2010. 312f. Tese (Doutorado em Desenvolvimento Regional) -Universidade de Santa Cruz do Sul - UNISC.

ALLEBRANDT, S. L.; RIBAS, T. A. M.; POLETTO, L.; FRIEDRICH, D. Controle social do desenvolvimento regional na região do Corede Missões na perspectiva dos agentes e atores sociais. Revista Brasileira de Gestão e Desenvolvimento Regional, v. 14, n. 2, jan/2018 (ed. especial), p. 38-69.

ALVES-MAZZOTTI, A. J.; GEWANDSZNAJDER, F. O MÉTODO NAS CIÊNCIAS NATURAIS E SOCIAIS: pesquisa quantitativa e qualitativa. São Paulo: Pioneira Thomson Learning, 2004.

BOISIER, S. DESARROLLO (LOCAL): ¿DE QUÉ ESTAMOS HABLANDO? Revista Transformaciones Globales, Instituciones y Políticas de Desarrollo Local. Editorial Homo Sapiens, Rosário, 2001.

BRANDÃO, Carlos. Território \& Desenvolvimento: as múltiplas escalas entre o local e o global. Campinas: Ed. Unicamp, 2007.

BÜTTENBENDER, P. L.; SIEDENBERG, D. R.; ALLEBRANDT, S. L. COREDES: estruturação, articulações intra e inter-regionais referenciais estratégicos e considerações críticas. In DALLABRIDA, V. R. (Org.). Governança territorial e desenvolvimento. Rio de Janeiro: Garamond Universitária, 2011. p. 311-338.

BÜTTENBENDER, P. L.; SIEDENBERG, D. R.; ALLEBRANDT, S. L. Conselhos regionais de desenvolvimento (coredes) RS: articulações regionais, referenciais estratégicos e considerações críticas. Revista Desenvolvimento Regional em Debate, ano 1, n. 1, p. 81-106, dez. 2011a.

COREDES. Propostas estratégicas para o desenvolvimento regional do Estado do Rio Grande do Sul. Passo Fundo: Passografic, 2010.

CORREIA, M.C. Que controle social na política de assistência social? Serviço Social \& Sociedade, Ano XXIII, 72: 43-60, 2002.

DALLABRIDA, V. R. Governança territorial e desenvolvimento: introdução ao tema. In DALLABRIDA, Valdir Roque (Org.). Governança territorial e desenvolvimento. Rio de Janeiro: Garamond Universitária, 2011. p. 15 a 38. 
A gestão territorial através do diálogo e da participação. IX Coloquio Internacional de Geocrítica sobre los problemas del mundo actual. soluciones y alternativas desde la geografía y las ciencias sociales. Porto Alegre. 2007.

DALLABRIDA, V. R.; MARCHESAN, J.; ROSSETO, A. M.; FILIPPIM, E. S. Governança nos territórios, ou governança territorial: distância entre concepções teóricas e a prática. In DALLABRIDA, Valdir Roque (Org.). Indicação geográfica e desenvolvimento territorial: reflexões sobre o tema e a potencialidade no Estado de Santa Catarina. São Paulo : Liberars, 2015. p. 23 a 39.

FRANCISCO NETO, D.; VILLELA, L. E. Controle Social local face as transformações e os impactos territoriais dos megaempreendimentos de Itaguaí (RJ). Revista Controle Social e Desenvolvimento Territorial (CSDT), v. 1, n.1, jan./jul. 2017.

GIL, A. C. Como elaborar projetos de pesquisas. São Paulo: Atlas, 2002.

MINAYO, M. C. S. (Org.). Pesquisa social: teoria, método e criatividade. Petrópolis: Vozes, 2001.

PAZ, R. D. O. Dimensões e indicadores de participação social na avaliação de programas habitacionais. São Paulo, 2002. Tese (Doutorado) Programa de Pós-Graduação em Serviço Social, Pontifícia Universidade Católica, São Paulo, 2002.

RIBAS, T. A. M. Controle social do desenvolvimento regional à luz da gestão social no âmbito do Corede missões. ljuí, 2017. 168f. Dissertação (Mestrado em Desenvolvimento) -Unijuí, ljuí.

RIO GRANDE DO SUL. Constituição Compilada do Estado do Rio Grande do Sul. 1987. Disponível em:

http://www2.al.rs.gov.br/dal/LegislaCAo/ConstituiCAoEstadual/tabid/3683/Default. Acesso em: 07 jul. 2016.

SIEDENBERG, D. R.; BÜTTENBENDER, P.; ALLEBRANDT, S. L. A trajetória do planejamento governamental no Rio Grande do Sul: dos primórdios aos Coredes. In DALLABRIDA, V. R. (Org.). Governança territorial e Desenvolvimento. Rio de Janeiro: Garamond Universitária, 2011. p. 191-201.

TENÓRIO, G. F. Cidadania, Território e atores sociais. Rio de Janeiro: FGV, 2016.

Gestão Social: conceito. In TENÓRIO, F. G.; KRONEMBERGER, T. S. (ORGs.) Gestão Social e conselhos gestores. Rio de Janeiro: FGV, 2016a.

Cidadania e desenvolvimento local: critérios e análise. Rio de Janeiro: FGV, 2012.

Cidadania e Desenvolvimento Local. ljuí: UNIJUI, 2007.

TENÓRIO, F. G. ; DUTRA, J. L. A. ; MAGALHÃES, C. M. R. de. Gestão social e desenvolvimento local: uma perspectiva a partir da cidadania deliberativa. In: ENANPAD, 28. , 2004. Anais. Curitiba: Anpad, 2004.

UNESP. Tipos de Revisão de Literatura. 2015. Disponível em: file:///E:/tipos-de-revisaode-literatura.pdf. Acessado em 26/07/2020. 